\title{
ELECTROCHIMIGA
}

\section{A DFT study of dioxymethylene adsorption on the copper (111) surface}

\author{
J.R.B. Gomes, J.A.N.F. Gomes* \\ CEQUP/Departamento de Química, Faculdade de Ciências da Universidade do Porto, Rua do Campo Alegre 687, \\ 4169-007 Porto, Portugal
}

Received 26 September 1998; received in revised form 30 March 1999

\begin{abstract}
Quantum density functional theory (DFT) results are reported for the adsorption of $\mathrm{H}_{2} \mathrm{CO}_{2}$ on the $\mathrm{Cu}$ (111) metallic surface as modelled by a $\mathrm{Cu}_{30}$ cluster. The calculations suggest that the $\mathrm{H}_{2} \mathrm{CO}_{2}$ species stabilises in the cross-bridge site with the two oxygen atoms located at different distances from the surface. $\mathrm{The}_{2} \mathrm{H}_{2} \mathrm{CO}_{2}$ species prefers an orientation with the OCO plane normal to the surface. Mulliken population analysis in the adsorbed species shows that there is charge donation from the copper surface to the double radical. The internal geometry of the adsorbed species is very different from that of the free molecules and this is the result of the strong interaction with the metal surface. The bonding of this adsorbate to the copper surface is essentially ionic. (C) 1999 Elsevier Science Ltd. All rights reserved.
\end{abstract}

Keywords: Heterogeneous catalysis; Theoretical study; $\mathrm{Cu}, \mathrm{H}_{2} \mathrm{CO}_{2}$; Methanol oxidation; Chemisorption

\section{Introduction}

In recent years, numerous experimental and theoretical investigations concerning the adsorption of small organic molecules on a variety of transition metal surfaces were carried out to gain new insights into the elementary steps of heterogeneous catalysis [1].

A full understanding of how these processes occur above metal surfaces is still lacking; for example, dioxymethylene has been proposed [2-4] as an intermediate in the reaction $\mathrm{H}_{2} \mathrm{CO}_{(\mathrm{a})} \rightarrow \mathrm{HCO}_{2(\mathrm{a})}$ but the experimental study of this adsorbed intermediate is quite difficult. The mode of coordination of this species is therefore an essential piece of information for a better understanding of the mechanism and selectivity in these reactions.

* Corresponding author. Tel.: + 351-2-608-2807; fax: + 351-2-608-2959.

E-mail address: jfgomes@fc.up.pt (J.A.N.F. Gomes)
Despite all the experimental and theoretical efforts, some reactional steps are still controversial this being the case for such important steps as the mechanism for the carbon-carbon bond forming in the polymerisation of ethylene, the identification of the intermediates in the methanol oxidation reaction, etc. Thus, further knowledge is needed about how these species adsorb on the metal surfaces, about the influence of co-adsorbed species and about the influence of the nature of the catalyst. This work is another contribution for the comprehension of these mechanisms.

The dioxymethylene species $\left(\mathrm{H}_{2} \mathrm{CO}_{2}\right)$ was observed experimentally by Madix and co-workers on $\mathrm{Cu}$ (110) [2,3] and on Ag (110) [4]. They have used a large number of experimental techniques (XPS, UPS, LEED, AES and TPRS) to perform these studies. The $\mathrm{H}_{2} \mathrm{CO}_{2}$ intermediate is formed after the reaction of $\mathrm{H}_{2} \mathrm{CO}$ with surface oxygen in the mechanism of conversion of formaldehyde to formate. In the case of adsorption on a silver (110) surface, those authors have performed the 
experiments on a pre-oxidised surface with labelled atomic oxygen $\left({ }^{18} \mathrm{O}\right)$. The presence of ${ }^{18} \mathrm{O}$ in $\mathrm{CO}_{2}$ and in desorbed $\mathrm{H}_{2} \mathrm{CO}$ shows that formaldehyde interacts with the atomic oxygen present on the surface, yielding $\mathrm{HCO}_{2}$ through the $\mathrm{H}_{2} \mathrm{CO}_{2}$ intermediate. Sexton et al. [5] using EELS, UPS and TDS have not observed the dioxymethylene intermediate on $\mathrm{Cu}$ (110). Yet, they do not state that $\mathrm{H}_{2} \mathrm{CO}_{2}$ is not present on the surface, but that the non-observation is due to a lower stability of this intermediate adsorbed on the $\mathrm{Cu}(110)$ surface. In some cases, this low stability makes it impossible to obtain experimental evidences for the existence of the $\mathrm{H}_{2} \mathrm{CO}_{2}$ species.

The presence of the dioxymethylene species in an almost symmetrical form was also found [6] after adsorption of formaldehyde on metal oxide surfaces. This is characterised by some strong absorption bands in the IR region between $1000-1200 \mathrm{~cm}^{-1}$.

The $\mathrm{H}_{2} \mathrm{CO}_{2}$ species was also observed in more recent works concerning the methanol adsorption on $\mathrm{Cu} / \mathrm{ZnO} /$ $\mathrm{Al}_{2} \mathrm{O}_{3}$ [7], on $\mathrm{Cu} / \mathrm{SiO}_{2}$ [8] and on $\mathrm{O} / \mathrm{Cu}$ (110) [9]. The presence of oxygen atoms in all these surfaces suggests that oxygen has an important role in the $\mathrm{H}_{2} \mathrm{CO}_{(\mathrm{a})} \rightarrow$ $\mathrm{H}_{2} \mathrm{CO}_{2}$ (a) $\rightarrow \mathrm{HCO}_{2(\text { a) }}$ reaction.

This paper is organised as follows. Section 2 describes theoretical details of the metal cluster and the computational method used. In Section 3 the calculated results for $\mathrm{H}_{2} \mathrm{CO}_{2}$ adsorbed on the copper (111) surface are presented, while, in Section 4, the most important conclusions obtained are summarised.

\section{Method}

In this work we use the $\mathrm{Cu}_{30}(14,8,8)$ cluster shown in Fig. 1. This three-layer cluster is a section of the ideal $\mathrm{Cu}$ (111) surface; the first layer is defined by 14 copper atoms and the second and third layers are composed of 8 copper atoms. The $\mathrm{Cu}-\mathrm{Cu}$ nearest neighbour distance is taken from the bulk and is $2.551 \AA$. This cluster belongs to the $C_{s}$ symmetry group. Small clusters were previously found to give a reasonable description of the copper (111) surface [10-13].

The calculations of the dioxymethylene interaction with the copper (111) surface were performed for two different orientations of the $\mathrm{H}_{2} \mathrm{CO}_{2}$ species; the crossbridge shown in Fig. 2(a) and the aligned-bridge shown in Fig. 2(b). In the cross-bridge orientation (also called long-bridge) the oxygen atoms of the dioxymethylene species are placed above the longer bridge site present in $\mathrm{Cu}$ (111) with one oxygen atom located at the fcc hollow site and the other oxygen atom at the hcp hollow site. The hep hollow site is the hollow site that has one copper atom of the second layer directly underneath it, while in the case of the fcc hollow site there is one copper atom directly underneath it only in the third layer. In the aligned-bridge orientation (also called short-bridge) the oxygen atoms of the dioxymethylene species are both located along the short bridge present in the $\mathrm{Cu}$ (111) surface. The oxygen atoms are free to move along the adsorption sites considered.

The geometry of the adsorbed $\mathrm{H}_{2} \mathrm{CO}_{2}$ species was optimised in the calculations. Only one restriction was imposed during these optimisations, the conservation of the mirror plane that contains the carbon, the oxygen and the copper atoms that define the long or the short bridges. In both cases the calculations were done with a starting geometry for the $\mathrm{H}_{2} \mathrm{CO}_{2}$ intermediate with a surface to oxygen distance equal for both oxygen atoms.

a)

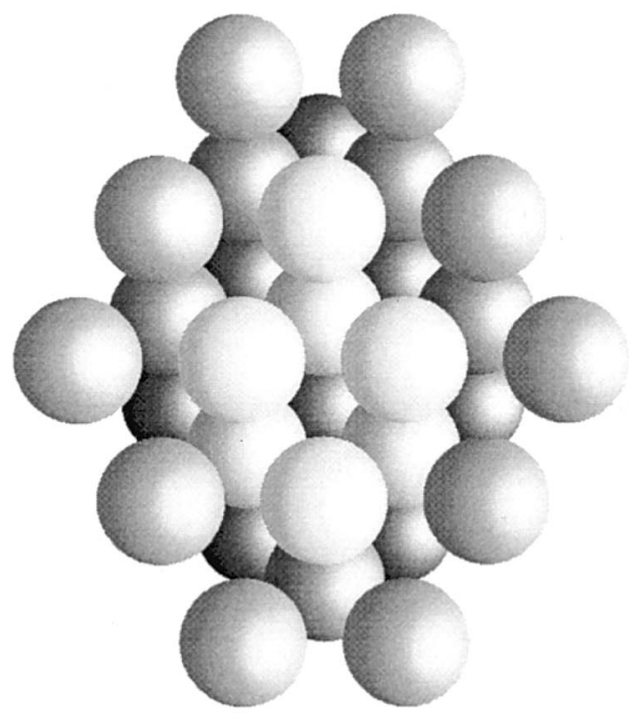

b)

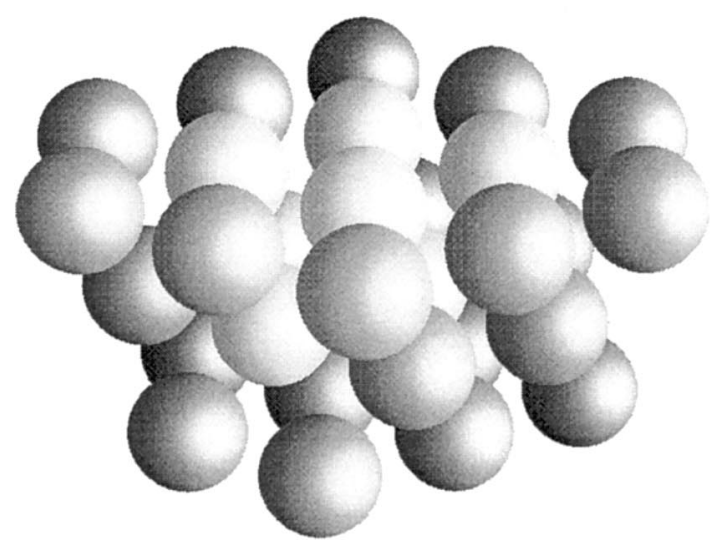

Fig. 1. Thirty atom metal cluster with three layers used to simulate the (111) copper surface. (a) Top view. (b) Side view. 
a)

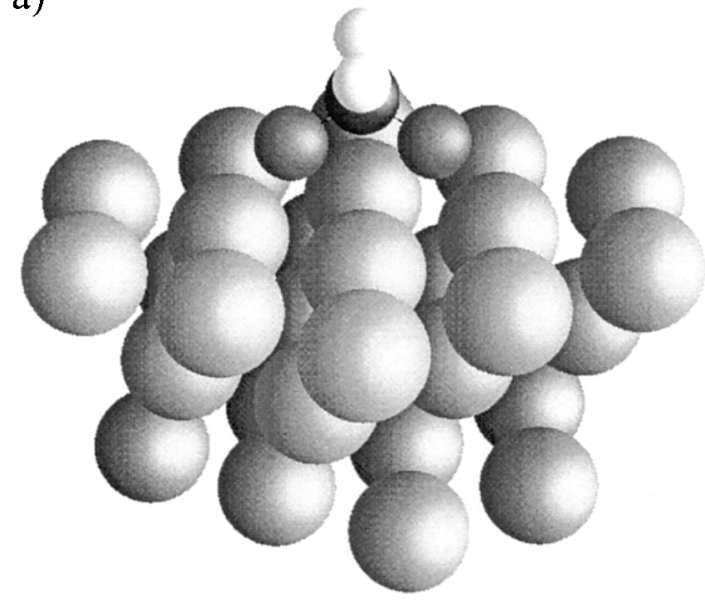

b)

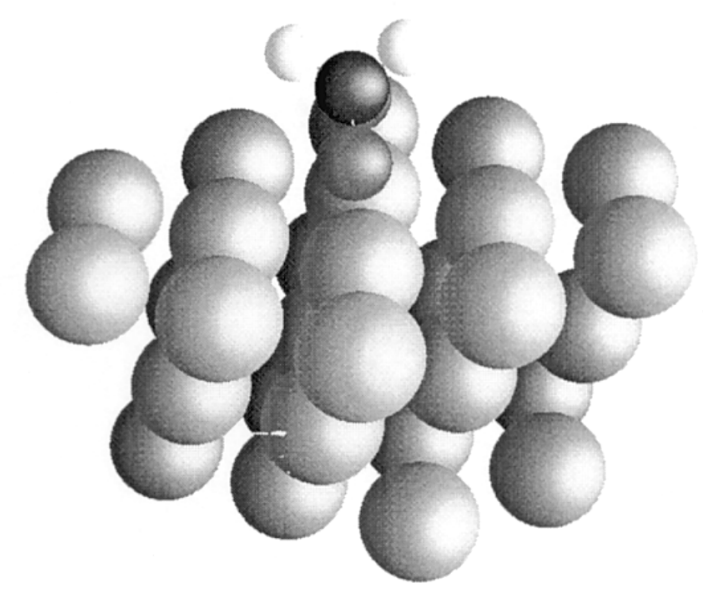

Fig. 2. Side view of the dioxymethylene species adsorbed on the $\mathrm{Cu}_{30}(14,8,8)$ cluster shown in Fig. 1. (a) Dioxymethylene species adsorbed on the cross-bridge site where the two oxygen atoms are located above two adjacent fcc and hcp hollow sites. (b) dioxymethylene species adsorbed on the aligned-bridge site where the two oxygen atoms are positioned above the short-bridge site present in the $\mathrm{Cu}$ (111) surface.

A method of calculation based on the density functional theory (DFT) was used to obtain the geometry and energy for the dioxymethylene species adsorbed on the copper (111) surface in the two orientations as explained above. The B3LYP hybrid method proposed by Becke [14] included in the Gaussian 94 [15] package was used. This method includes a mixture of HartreeFock (HF) and DFT exchange terms associated with the gradient corrected correlation functional of Lee, Young and Parr [16].

The four first layer and three second layer metal atoms closest to the substrate (light grey atoms depicted in Fig. 1) are described by the LANL2DZ basis set which treats the outer 19 electrons of copper atoms with a double zeta basis set and the inner $1 \mathrm{~s}, 2 \mathrm{~s}$ and $2 \mathrm{p}$ electrons with the effective core potential of Hay and Wadt [17]. In the other 23 metal atoms only the $4 \mathrm{~s}$ electron is treated explicitly, while their inner electrons are included in the effective core potential of Bagus et al. [18]. The non-metallic atoms $(\mathrm{O}, \mathrm{C}$ and $\mathrm{H})$ are described by the $6-31 \mathrm{G}^{* *}$ basis set of double zeta quality with $\mathrm{p}$ polarisation functions in the hydrogen atoms and d polarisation functions in carbon and oxygen atoms. Calculations were done only for the ground state configurations.

\section{Results}

Table 1 lists the computed geometry results of the free $\mathrm{H}_{2} \mathrm{CO}_{2}$ and $\left[\mathrm{H}_{2} \mathrm{CO}_{2}\right]^{2-}$ species. As expected, a distorted tetrahedral like geometry is found.
If a comparison is made between the results obtained for the radical and those obtained for the anion, the influence of the extra electron in each of the two oxygen lone pairs is observed in the latter case. In fact a stronger repulsion between the oxygen atoms of the anion causes the increase of the $\mathrm{O}-\mathrm{C}-\mathrm{O}$ angle and the subsequent increase in the $\mathrm{C}-\mathrm{H}$ bond length and decrease in the $\mathrm{H}-\mathrm{C}-\mathrm{H}$ angle. This repulsive effect causes a destabilisation of the anion by approximately $380 \mathrm{~kJ}$ $\mathrm{mol}^{-1}$ relatively to the radical.

Table 2 summarises the computed energy, geometry and Mulliken charge for $\mathrm{H}_{2} \mathrm{CO}_{2}$ adsorbed on the aligned-bridge and on the cross-bridge sites of the $\mathrm{Cu}$ (111) surface. The calculated adsorption energy, obtained as the difference between the total energy of the $\mathrm{Cu}_{30}-\mathrm{H}_{2} \mathrm{CO}_{2}$ aggregate and the total energy of the infinitely separated fragments $\left(\mathrm{Cu}_{30}\right.$ and $\left.\mathrm{H}_{2} \mathrm{CO}_{2}\right)$, is $342.9 \mathrm{~kJ} \mathrm{~mol}^{-1}$ for the aligned-bridge site and $415.3 \mathrm{~kJ}$ $\mathrm{mol}^{-1}$ for the cross-bridge site. The geometry of this

Table 1

Geometry and energy of the optimised free $\mathrm{H}_{2} \mathrm{CO}_{2}$ and $\left[\mathrm{H}_{2} \mathrm{CO}_{2}\right]^{2-}$ species

\begin{tabular}{lcc}
\hline & $\mathrm{H}_{2} \mathrm{CO}_{2}$ & {$\left[\mathrm{H}_{2} \mathrm{CO}_{2}\right]^{2-}$} \\
\hline Energy (a.u.) & -189.587 & -189.443 \\
Distance (CO) $(\stackrel{\AA}{\mathrm{A}})$ & 1.331 & 1.32 \\
Distance $(\mathrm{CH})(\stackrel{\AA}{\mathrm{A}})$ & 1.130 & 1.32 \\
Angle $(\mathrm{OCO})\left(^{\circ}\right)$ & 107.3 & 123.4 \\
Angle $(\mathrm{HCH})\left(^{\circ}\right)$ & 101.9 & 93.6 \\
Angle $(\mathrm{OCH})\left(^{\circ}\right)$ & 111.9 & 108.9 \\
\hline
\end{tabular}


Table 2

Energy, geometry and total Mulliken charge for the $\mathrm{H}_{2} \mathrm{CO}_{2}$ species adsorbed on the aligned-bridge and cross-bridge sites of the $\mathrm{Cu}(111)$ surface $^{\mathrm{a}}$

\begin{tabular}{lcc}
\hline $\mathrm{H}_{2} \mathrm{CO}_{2} / \mathrm{Cu}(111)$ & Aligned-bridge & Cross-bridge \\
\hline $\begin{array}{c}\text { Adsorbed energy }(\mathrm{kJ} \\
\text { mol-1) }\end{array}$ & -342.9 & -415.3 \\
Distance $\left(\right.$ surf- $\left.\mathrm{O}_{1}\right)(\AA)$ & 1.915 & 1.640 \\
Distance $\left(\right.$ surf- $\left.\mathrm{O}_{2}\right)(\AA)$ & 1.915 & 1.653 \\
Distance $\left(\mathrm{CuO}_{1}\right)(\AA)$ & 1.917 & 1.954 \\
Distance $\left(\mathrm{CuO}_{2}\right)(\AA)$ & 1.917 & 1.964 \\
Distance $\left(\mathrm{CO}_{1}\right)(\AA)$ & 1.393 & 1.397 \\
Distance $\left(\mathrm{CO}_{2}\right)(\AA)$ & 1.393 & 1.396 \\
Distance $(\mathrm{CH})(\AA)$ & 1.111 & 1.107 \\
Angle $(\mathrm{OCO})\left({ }^{\circ}\right)$ & 116.5 & 10.6 \\
Angle $(\mathrm{HCH})\left({ }^{\circ}\right)$ & 106.7 & 109.5 \\
Angle $\left(\mathrm{O}_{1} \mathrm{CH}\right)\left({ }^{\circ}\right)$ & 108.3 & 109.3 \\
Angle $\left(\mathrm{O}_{2} \mathrm{CH}\right)\left({ }^{\circ}\right)$ & 108.3 & -0.64 \\
q (adsorbate) $($ a.u. $)$ & -0.65 & \\
\hline
\end{tabular}

a Negative values for the adsorption energy are exothermic.

adsorbed species is very different from the ones obtained for the free molecules. The $\mathrm{C}-\mathrm{O}$ bond length is larger and the $\mathrm{C}-\mathrm{H}$ bond length is shorter in the adsorbed forms. Both species are strongly attached to the surface and this causes the $\mathrm{CO}$ bond length to be higher for the adsorbed species than for the free species. The weaker $\mathrm{CO}$ bonds produces two stronger $\mathrm{CH}$ bonds.

No experimental or theoretical data concerning $\mathrm{H}_{2} \mathrm{CO}_{2}$ adsorption, for comparison purposes, were found in the literature. However, a comparison could be made with experimental results obtained for a similar species, formate. For formate, $\mathrm{HCO}_{2}^{-}$, an experimental copper-oxygen distance of $1.98 \pm 0.05 \AA$ has been reported [19] for the bidentate adsorption on the aligned-bridge site of copper (100) and of copper (110). The value found for the $\mathrm{O}-\mathrm{Cu}$ distance for $\mathrm{H}_{2} \mathrm{CO}_{2}$ adsorbed on the aligned-bridge of copper (111) is in good agreement with the experimental value obtained for adsorbed formate. Since the short-bridge length is the same for the three surfaces of copper [(100), (110) and (111)], we can conclude that the influence of the extra hydrogen atom in $\mathrm{H}_{2} \mathrm{CO}_{2}$ is minimal.

The non-equivalence of the two hollow sites (one hcp and one fcc) for the cross-bridge site causes the $\mathrm{O}-\mathrm{Cu}$ surface distances to be different. The difference is not significant though, the shorter O-Cu distance (1.640 $\mathrm{A})$ corresponds to the oxygen atom which is located above the hcp hollow site and the longer distance $(1.653 \AA)$ to the oxygen atom which is located above the fcc hollow site. The nearest neighbour distances are 1.954 and $1.964 \AA$ Å, respectively.

The internal geometry of the adsorbate is practically the same for both adsorption sites. The $\mathrm{CO}$ bond lengths are close to $1.10 \AA$. The internal angles are similar too and the largest deviation is found for the OCO angle $\left(\approx 6^{\circ}\right)$.

Upon adsorption, there is a charge transfer from the metal surface to the dioxymethylene species. After adsorption, the total charge transferred to the radical is close to $0.65 e$ which is in agreement with the strong interaction of $\mathrm{H}_{2} \mathrm{CO}_{2}$ with the surface.

The dependence of the adsorption energy on the $\mathrm{O}$-surface distance is presented in Fig. 3 for $\mathrm{H}_{2} \mathrm{CO}_{2}$ adsorption on the two sites considered. For adsorption on the cross-bridge site, the O-surface distance is the one from the oxygen atom located above the hcp hollow site to the first layer. The adsorption energy variation is smaller for the cross-bridge site.

The variation of the adsorption energy with the tilting of the OCO plane of the $\mathrm{H}_{2} \mathrm{CO}_{2}$ species is shown in Fig. 4. This figure shows that there is a destabilisation if the OCO plane is tilted from the normal to the surface. For $\mathrm{H}_{2} \mathrm{CO}_{2}$ adsorption on the aligned-bridge site, the tilting effect is much higher than for $\mathrm{H}_{2} \mathrm{CO}_{2}$ adsorption on the cross-bridge site. The tilting of the OCO plane of $\mathrm{H}_{2} \mathrm{CO}_{2}$ adsorbed on the aligned-bridge site leads to a geometry where one of the hydrogen atoms is closer to one of the hollow sites, while the adsorption on the cross-bridge site leads to a geometry where one of the hydrogen atoms is closer to one copper atom of the $\mathrm{Cu}$ (111) short-bridge site. For a tilt angle of $25^{\circ}$ the destabilisation in energy is approximately $290 \mathrm{~kJ} \mathrm{~mol}^{-1}$ for adsorption on the alignedbridge site and only $6 \mathrm{~kJ} \mathrm{~mol}^{-1}$ for adsorption on the

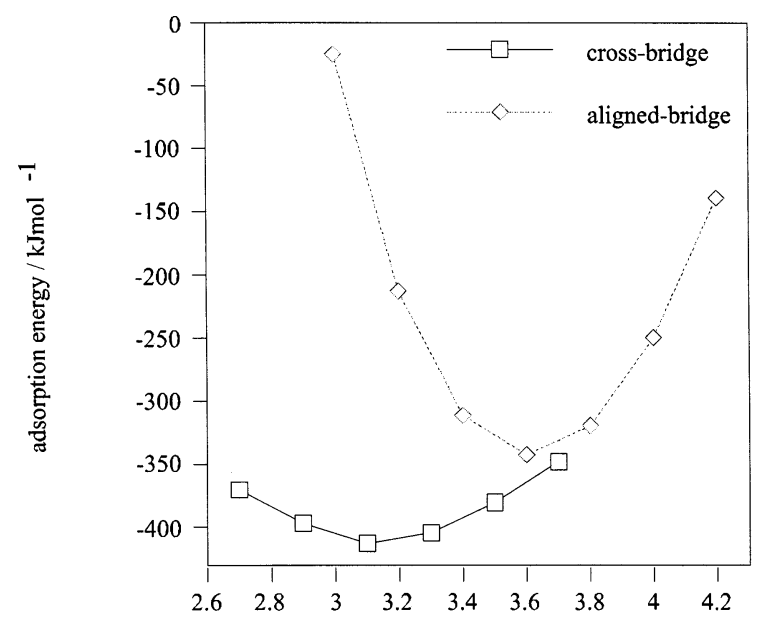

adsorbate-surface distance / a. u.

Fig. 3. Energy of the $\mathrm{H}_{2} \mathrm{CO}_{2}$ species adsorbed on the alignedbridge and cross-bridge sites of copper (111) surface at various $\mathrm{O}$-surface distances. For $\mathrm{H}_{2} \mathrm{CO}_{2}$ adsorbed on the cross-bridge site, the $\mathrm{O}$-surface distance is the distance of the oxygen adsorbed on the hcp site to the surface. 




tilt angle / degree

Fig. 4. Adsorption energy variation with the tilting of the OCO plane of the $\mathrm{H}_{2} \mathrm{CO}_{2}$ molecule from the surface normal for $\mathrm{H}_{2} \mathrm{CO}_{2}$ adsorption on the aligned-bridge and cross-bridge sites of the copper (111) surface. For adsorption on the aligned-bridge site, negative tilting angles mean tilting of the OCO plane of the adsorbed species with one hydrogen atom approaching the fcc hollow site while positive tilting angles mean tilting of the OCO plane of the adsorbed species with one hydrogen atom approaching the hcp hollow site.

cross-bridge site. The larger effect observed for adsorption on the aligned-bridge site is a consequence of the direct binding of the oxygen atoms to the copper atoms. Tilting the OCO plane causes the breaking of the symmetry between the atomic orbitals of the copper, oxygen and carbon atoms. For adsorption on the cross-bridge site, this effect is smaller due to the binding of the oxygen atoms to the hcp and fcc hollow sites. These sites behave like a pool of electrons, were interactions involve more than one copper atom. The small difference between the adsorption energies of the tilted and upright $\mathrm{H}_{2} \mathrm{CO}_{2}$ species adsorbed on the crossbridge site means that these molecules may possibly be observed tilted at low coverage. This figure also shows that the two hollow sites (hcp and fcc) are very similar. The energy variation with the tilting angle for $\mathrm{H}_{2} \mathrm{CO}_{2}$ adsorbed on the aligned-bridge site is practically the same if one hydrogen atom approaches the hcp or the fcc hollow site.

In Fig. 5, the dipole moment variation against the distance of the adsorbates to the metal surface is plotted. We only plotted the distances close to the calculated equilibrium distances for the $\mathrm{H}_{2} \mathrm{CO}_{2}$ species adsorbed on the two different adsorption sites considered. Only the component of the dipole moment normal to the surface is considered. The linearity of these curves indicates a bond between the adsorbate and the metal surface with a mainly ionic character. An ionic bond was also observed [11,20] for other oxygen bonded species such as methoxy and hydroxy radicals. The slope of these curves gives an idea of the charge in the adsorbed species. The slopes obtained are -1.68 and -1.43 for adsorption on the aligned-bridge and cross-bridge sites, respectively. García-Hernández et al. [21] observed, for a negative charge placed above a cavity or above an atom of the Pt (111) surface, that this method overestimates the charge in the adsorbate by $35-40 \%$. The charge in the adsorbed $\mathrm{H}_{2} \mathrm{CO}_{2}$ species should have a value between the calculated Mulliken charge and the slope of the dipole moment variation with the adsorbate-surface distance.

The $\left[\mathrm{H}_{2} \mathrm{CO}_{2}\right]^{2-}$ species is adsorbed on the $\mathrm{Cu}$ (111) surface similarly to the neutral $\mathrm{H}_{2} \mathrm{CO}_{2}$ species (results not shown). These findings were also reported by Olivera et al. [22] for the adsorption of small ions $\left(\mathrm{OH}^{+}\right.$, $\mathrm{OH}^{-}, \mathrm{SO}_{3}^{2-}, \mathrm{SO}_{4}^{2-}$, etc.) in the low coverage limit on silver.

\section{Conclusions}

Small metal clusters have been extensively used for theoretical studies in surface chemistry. In many instances, these clusters were shown to be reasonably good models for the metallic surfaces. On the other hand, the properties of the cluster itself may be important as it is believed that in certain catalysts, where the active metal is supported on a metal oxide, the catalytic activity is solely due to the very small metal particles.



Fig. 5. Variation of the dipole moment component normal to the surface with the distance from the surface of the $\mathrm{H}_{2} \mathrm{CO}_{2}$ species at the aligned-bridge site and at the cross-bridge site. 
The DFT results reported above show that the $\mathrm{H}_{2} \mathrm{CO}_{2}$ species is adsorbed on the cross-bridge site of the copper (111) surface. When adsorbed on the aligned-bridge site, the $\mathrm{H}_{2} \mathrm{CO}_{2}$ species is destabilised by ca. $70 \mathrm{~kJ} \mathrm{~mol}^{-1}$ when compared with the adsorption of the same species on the cross-bridge site. It was also found that these species are adsorbed with the OCO plane of the these molecules normal to the metal surface. Tilting the $\mathrm{OCO}$ plane of $\mathrm{H}_{2} \mathrm{CO}_{2}$ adsorbed on the aligned-bridge site causes a large destabilisation effect. The same is not observed for $\mathrm{H}_{2} \mathrm{CO}_{2}$ adsorption on the cross-bridge site, where only a small decrease in the adsorption energy is observed. The energy difference between the free molecules $\mathrm{H}_{2} \mathrm{CO}_{2}$ and $\left[\mathrm{H}_{2} \mathrm{CO}_{2}\right]^{2-}$ is $380 \mathrm{~kJ} \mathrm{~mol}^{-1}$, the radical being more stable. The energy gap should be close to the difference between adsorbed $\mathrm{H}_{2} \mathrm{CO}_{2}$ and $\left[\mathrm{H}_{2} \mathrm{CO}_{2}\right]^{2-}$, since both species have the same geometry after adsorption on the $\mathrm{Cu}$ (111) surface.

The adsorption energy for the $\mathrm{H}_{2} \mathrm{CO}_{2}$ species is large $\left(415.3 \mathrm{~kJ} \mathrm{~mol}^{-1}\right)$. The geometry of the adsorbed species is very different from that calculated for the free molecules and it indicates a strong interaction of these species with the metal surface.

The total Mulliken charge found for the adsorbed $\mathrm{H}_{2} \mathrm{CO}_{2}$ molecule is similar for adsorption on the two sites considered. There is charge donation from the metal surface to the $\mathrm{H}_{2} \mathrm{CO}_{2}$ species by approximately $0.65 e$.

From the results of the variation of the dipole moment with the distance of the adsorbate to the metal surface it was found that the bonding type of the species considered in both adsorption sites of the copper (111) surface is predominantly ionic.

From our experience, we know that Mulliken charges are generally inferior to the real charge in the adsorbate. In a previous work [21], the opposite effect was also observed for charges obtained from the slope of dipole moment versus adsorbate-surface distance curves. Therefore, we conclude that the real charge in the adsorbed $\mathrm{H}_{2} \mathrm{CO}_{2}$ species should be larger than 0.65 $e$ and smaller than the slope of the dipole moment variation with the adsorbate-surface distance.

\section{Acknowledgements}

Financial support from the Fundação para a Ciência e Tecnologia (Lisbon) and project PRAXIS/3/3.1/
MMA/1780/95 is acknowledged. JRBG thanks PRAXIS for a doctoral scholarship (BD/5522/95).

\section{References}

[1] J.M. Thomas, W.J. Thomas, Principles and Practice of Heterogeneous Catalysis, Weinheim, Germany, 1997.

[2] M. Bowker, R.J. Madix, Surf. Sci. 102 (1981) 542.

[3] I.E. Wachs, R.J. Madix, Surf. Sci. 84 (1979) 375.

[4] M.A. Barteau, M. Bowker, R.J. Madix, Surf. Sci. 94 (1980) 303.

[5] B.A. Sexton, A.E. Hughes, N.R. Avery, Surf. Sci. 155 (1985) 366.

[6] G. Busca, J. Lamotte, J.-C. Lavalley, V. Lorenzelli, J. Am. Chem. Soc. 109 (1987) 5197.

[7] N.D. Lazo, D.K. Murray, M.L. Kieke, J.F. Haw, J. Am. Chem. Soc. 114 (1992) 8552.

[8] D.B. Clarke, D.K. Lee, M.J. Saudoval, A.T. Bell, J. Catal. 150 (1994) 81.

[9] A.H. Jones, S. Poulston, R.A. Bennet, M. Bowker, Surf. Sci. 380 (1997) 31.

[10] J.R.B. Gomes, J.A.N.F. Gomes, J. Mol. Struct. (Theochem) 463 (1999) 163.

[11] J.R.B. Gomes, J.A.N.F. Gomes, Surf. Sci. 432 (1999) 279.

[12] A. Michalak, M. Witko, K. Hermann, J. Mol. Catal. A: Chem. 112 (1997) 213.

[13] A. Clotet, G. Pacchioni, Surf. Sci. 346 (1996) 91.

[14] A.D. Becke, J. Chem. Phys. 98 (1993) 5648.

[15] M.J. Frisch, G.W. Trucks, H.B. Schlegel, P.M.W. Gill, B.G. Johnson, M.A. Robb, J.R. Cheeseman, T. Keith, G.A. Petersson, J.A. Montgomery, K. Raghavachari, M.A. Al-Laham, V.G. Zakrzewski, J.V. Ortiz, J.B. Foresman, J. Cioslowski, B.B. Stefanov, A. Nanayakkara, M. Challacombe, C.Y. Peng, P.Y. Ayala, W. Chen, M.W. Wong, J.L. Andres, E.S. Replogle, R. Gomperts, R.L. Martin, D.J. Fox, J.S. Binkley, D.J. Defrees, J. Baker, J.P. Stewart, M. Head-Gordon, C. Gonzalez, J.A. Pople, Gaussian 94, Revision D.4, Gaussian, Inc., Pittsburgh PA, 1995.

[16] C. Lee, W. Yang, R.G. Parr, Phys. Rev. B 37 (1980) 785.

[17] P.J. Hay, W.R. Wadt, J. Chem. Phys. 82 (1985) 270.

[18] P.S. Bagus, C.W. Bauschlicher Jr., C.J. Nelin, B.C. Laskowski, M. Seel, J. Chem. Phys. 81 (1984) 3594.

[19] D.P. Woodruff, C.F. McConville, A.L.D. Kilcoyne, Th. Lindner, J. Somers, M. Surman, G. Paolucci, A.M. Bradshaw, Surf. Sci. 201 (1988) 228.

[20] K. Hermann, M. Witko, L.G.M. Petterson, P. Siegbahn, J. Chem. Phys. 99 (1993) 610.

[21] M. García-Hernández, P.S. Bagus, F. Illas, Surf. Sci. 409 (1998) 69.

[22] P.P. Olivera, E.M. Patrito, H. Sellers, E. Schustorovich, J. Mol. Catal. A: Chem. 119 (1997) 275. 